\title{
Comparing bivalent and quadrivalent human papillomavirus vaccines: economic evaluation based on transmission model
}

\author{
(C) (1) $\Theta$ OPEN ACCESS
}

\author{
Mark Jit mathematical modeller ${ }^{1}$, Ruth Chapman mathematical modeller ${ }^{1}$, Owain Hughes clinical \\ research fellow ${ }^{2}$, Yoon Hong Choi mathematical modeller ${ }^{1}$
}

${ }^{1}$ Health Protection Agency, London NW9 6BT, UK; ${ }^{2}$ Institute of Child Health, London WC1N 1EH

\begin{abstract}
Objectives To compare the effect and cost effectiveness of bivalent and quadrivalent human papillomavirus (HPV) vaccination, taking into account differences in licensure indications, protection against non-vaccine type disease, protection against disease related to HPV types 6 and 11, and reported long term immunogenicity.

Design A model of HPV transmission and disease previously used to inform UK vaccination policy, updated with recent evidence and expanded to include scenarios where the two vaccines differ in duration of protection, cross protection, and end points prevented.

Setting United Kingdom.

Population Males and females aged 12-75 years.

Main outcome measure Incremental cost effectiveness ratios for both vaccines and additional cost per dose for the quadrivalent vaccine to be equally cost effective as the bivalent vaccine.

Results The bivalent vaccine needs to be cheaper than the quadrivalent vaccine to be equally cost effective, mainly because of its lack of protection against anogenital warts. The price difference per dose ranges from a median of $£ 19$ (interquartile range £12-£27) to £35 (£27-£44) across scenarios about vaccine duration, cross protection, and end points prevented (assuming one quality adjusted life year (QALY) is valued at $£ 30000$ and both vaccines can prevent all types of HPV related cancers).
\end{abstract}

Conclusions The quadrivalent vaccine may have an advantage over the bivalent vaccine in reducing healthcare costs and QALYs lost. The bivalent vaccine may have an advantage in preventing death due to cancer. However, considerable uncertainty remains about the differential benefit of the two vaccines.

\section{Introduction}

Human papillomavirus (HPV) infection is a necessary cause of cervical cancer ${ }^{1}$ and is associated with other anogenital cancers ${ }^{2}$ and anogenital warts. It may also be involved in some head and neck cancers. ${ }^{3}$ Two vaccines that protect against HPV infection and disease are now licensed for use in the United States and the European Union. Cervarix is a bivalent vaccine targeting HPV types 16 and 18, which are responsible for over $70 \%$ of cervical cancer cases worldwide. ${ }^{4}$ Gardasil is a quadrivalent vaccine that again targets HPV types 16 and 18, but also targets HPV types 6 and 11, which cause most cases of anogenital warts $^{5}$ as well as recurrent respiratory papillomatoses. ${ }^{6}$ The quadrivalent vaccine has also shown protection against precursor lesions to vulval, vaginal, and anal cancers. ${ }^{7}$ More recently, the bivalent vaccine has shown efficacy against anal infection, suggesting potential protection against anal cancer. ${ }^{9}$ Both the quadrivalent and bivalent vaccines show varying degrees of protection against oncogenic HPV types not included in the vaccines. $^{101112}$

Several countries procure one of the vaccines for publicly funded vaccination programmes. For instance, Australia, Denmark, and France procure the quadrivalent vaccine, whereas the UK and the Netherlands use the bivalent vaccine. The choice between vaccines is not straightforward as they differ in valency, licensed indications, cross protective potential, and long term immunogenicity, ${ }^{13}$ as well as possible tender price.$^{14}$ In the UK a publicly funded HPV vaccination programme was started in 2008 , with routine vaccination offered to schoolgirls aged 12-13 years and a two year catch-up for girls up to the age of 18 years. ${ }^{15}$ A competitive adjudication process informed by economic modelling ${ }^{16}$ resulted in a three year tender for the programme being awarded to the manufacturers of the bivalent vaccine.

The previous economic model suggested that the bivalent vaccine would have to be about $£ 15-£ 23$ cheaper per dose to be equally cost effective as the quadrivalent vaccine because of the lack of protection against anogenital warts. ${ }^{16}$ Since then, 
further evidence has emerged to differentiate the two vaccines in terms of vaccine efficacy in long term follow-up of vaccinated cohorts as well as protection against genital warts, non-vaccine HPV types, and non-cervical diseases related to HPV infection. In addition, recent epidemiological and modelling studies have enabled better estimates of the burden of cervical cancers, ${ }^{17}$ anogenital warts, ${ }^{18}{ }^{19}$ recurrent respiratory papillomatoses,${ }^{20}$ low grade lesions due to HPV 6 and $11,{ }^{21}$ and the apparent increase in diseases caused by non-vaccine HPV types after vaccination because of misattribution of disease to vaccine HPV types (unmasking). ${ }^{22}$

Here we discuss key issues affecting the comparative cost effectiveness of the two vaccines and use the most recent evidence to estimate how much their price must differ for them to be equally cost effective.

\section{Methods}

\section{Methodological assumptions}

A previously described transmission dynamic model of infection and disease related to specific types of HPV (incorporating adenocarcinomas, non-cervical cancers, and cancers not due to HPV types 16 and 18$)^{16}$ was adjusted in order that the pre-vaccination burden of disease incorporated data from recently published studies (see below). The incremental costs and gains in quality adjusted life years (QALYs) of an HPV vaccination programme using either the quadrivalent or bivalent vaccine were estimated. Vaccination was assumed to start in September 2008 with a school based programme for 12 year old girls, and a catch-up campaign up to age 18 staggered over two years. ${ }^{23}$ In order to simulate a decision implemented in September 2011, the costs and benefits of the initial three years of vaccination were not counted. Costs were inflated to 2008-9 prices using the Hospital and Community Health Services pay and prices index. ${ }^{24}$ Costs and benefits were discounted at $3.5 \%$ per year in the base case, with a time horizon of 100 years. All costs were estimated from the perspective of the healthcare provider. One QALY was assumed to be valued at $£ 20000-£ 30$ 000 , which is the threshold for cost effectiveness used by the National Institute for Health and Clinical Excellence (NICE). ${ }^{25}$

\section{Disease due to oncogenic HPV types Cervical cancer}

A multisite study of HPV prevalence in women with cervical cancer indicated that the proportion of cervical cancers in England due to vaccine HPV types may be higher than previously estimated. ${ }^{17}$ DNA of HPV type 16 or 18 was detected in $76.4 \%$ (95\% confidence interval $71.0 \%$ to $81.1 \%$ ) of specimens of residual squamous cell carcinoma and $81.9 \%$ ( $73.2 \%$ to $88.2 \%$ ) of residual adenocarcinoma specimens. Some of these specimens also had DNA from other high risk HPV types which may have caused the cancer; however, the possibility of the cancer not being caused by HPV 16 or 18 is subsequently adjusted for in our model (see subsection on unmasking, below). Furthermore, $4.2 \%$ of squamous cell carcinomas and $4.8 \%$ of adenocarcinomas had no detectable high risk HPV. If it is assumed that this was due to lack of assay sensitivity and that the missing types had the same distribution as specimens with high risk HPV types detected, then the proportion of cancers attributable to HPV 16 and 18 would rise further. Hence the rate at which individuals develop invasive cancer in our previous model was increased by an appropriate amount in order to achieve a higher proportion of vaccine preventable cancers, ensuring that the median proportion of cancers attributable to HPV 16 or 18 was within the range suggested in the study.

\section{Non-cervical cancer}

Currently there are data indicating that quadrivalent vaccination protects against intraepithelial neoplasias of the vulva, vagina, and anus that can progress to invasive carcinoma. ${ }^{78}$ In addition, penile and oropharyngeal cancers have been linked with infection with HPV 16 or $18 .{ }^{2}$ The bivalent vaccine had not been evaluated for non-cervical end points in clinical trials at the time this analysis was conducted, although there seemed no reason to expect that it would not show protection against the same end points related to HPV 16 and 18 as the quadrivalent vaccine. Recently, the bivalent vaccine has been shown to protect against anal infection. ${ }^{9}$

Two scenarios about the effect of vaccination on non-cervical cancers were considered. In the optimistic scenario, it was assumed that all cancers attributable to HPV 16 and 18 were potentially preventable by vaccination. Protection against cancers due to other HPV types for which the vaccines have cross protective efficacy was assumed in some scenarios (see table $1 \Downarrow$ ). In the pessimistic scenario, it was assumed that the quadrivalent vaccine protected against cervical, vulval, vaginal, and anal cancers, and the bivalent vaccine protected against cervical cancers only. The proportion of these cancers caused by HPV 16, HPV 18, and non-vaccine HPV types was determined using the most recent and comprehensive meta-analyses available (see appendix 1 on bmj.com for details).

The acquisition of HPV and natural course of HPV related cancers at non-cervical sites are poorly understood. Hence, it is difficult to construct a model of HPV infection and disease in these sites that accurately captures the underlying biological processes. As a simplification, we assumed that the incidence of HPV attributable non-cervical cancers (by age and year after vaccination) will decrease at the same rate (proportionately) as cervical cancer, as predicted by our transmission dynamic model. Hence, slower developing cancers (which occur later in life) will be reduced only many years after vaccination. This is because they are more likely to be the result of HPV acquisition many years before cancer onset. The incidence of these cancers was obtained from cancer registration statistics for England in 2007. ${ }^{26}$

\section{Disease due to HPV 6 and 11 Anogenital warts}

Recently, the annual number of unique warts episodes leading to patient attendances at either sexual health or general practitioner clinics in England was estimated at about $156000 .{ }^{19}$ Older studies based in specialist dermatology or gynaecology clinics that tested HPV DNA in condylomas of anogenital warts patients have found that HPV 6 or 11 is present in well over $90 \%$ of them. ${ }^{27}{ }^{28}$ However, it is not certain whether HPV 6 or 11 caused the warts since other HPV types were often also detected. A more recent study based in a Swedish sexual health clinic found that HPV 6 and 11 were present only in $60 \%$ of warts cases. ${ }^{29}$ Trials of the quadrivalent HPV vaccine, which arguably provide the largest and best characterised cohorts, found that the vaccine has an efficacy of $99 \%$ against condylomas with vaccine HPV types present but only $82.8 \%$ against all condylomas regardless of HPV type. ${ }^{5}$

We estimated the median number of wart episodes attributable to HPV 6 and 11 each year to be 117000 (range 105 000-135 000). This estimate was made using a previously described model of warts associated with HPV 6 and $11^{30}$ that we refitted 
to include recent data on the age distribution of these wart episodes. ${ }^{19}$ Using this refitted model, we selected the 330 best fitting scenarios using the same definition of a good fitting scenario as in our previous model (that is, a sum of squared residual cut-off of 4). The resulting range of values that these scenarios produce for the fraction of warts episodes attributable to HPV 6 and 11 (67-86\% of episodes) lies within the range of uncertainty in the published literature (cited above).

\section{Low grade screens}

Based on a recent model, ${ }^{21}$ we estimated that infection with HPV 6 or 11 increases the risk per cervical screen of an abnormal (mild) smear by 0.054 (95\% confidence interval 0.048 to 0.060) compared with not being infected with HPV.

Furthermore, data from the National Cervical Cancer Screening Programme allowed us to estimate that each such smear has a $2.3 \%(2.1 \%$ to $2.5 \%)$ risk of resulting in a colposcopy. These estimates were incorporated into the model as an incremental benefit of quadrivalent vaccination.

\section{Recurrent respiratory papillomatoses}

Results of a survey of otorhinolaryngologists in the UK were used to estimate that every year an additional 29.9 adult and 29.6 juvenile cases of recurrent respiratory papillomatoses occur. ${ }^{20}$ Also, $2 \%$ of juvenile cases result in death. In the optimistic scenario (where HPV vaccines prevent penile and oropharyngeal cancer even though there is no direct evidence from clinical trials for this), it was assumed that use of the quadrivalent vaccine would reduce the incidence of new cases at the same rate as the reduction in anogenital warts due to HPV 6 and 11 .

\section{Vaccine effects Coverage}

By April 2010, 84.1\% of the first cohort of 12-13 year old schoolgirls had received all three doses of HPV vaccine, $87.7 \%$ had received at least two doses, and $89.8 \%$ had received at least one dose. ${ }^{15}$ However, uptake during the first year may have been boosted by the media attention attached to both HPV vaccination and cervical screening in 2008. It was conservatively assumed that an annual average of $80 \%$ of $12-13$ year old schoolgirls received the full course of vaccination. The cost of purchasing the doses was inflated by $10 \%$ to account for doses given to girls not receiving the full three doses (that is, a proportion of the remaining $20 \%$ of girls). Coverage for the catch-up cohorts was assumed to be $65 \%$ for $13-17$ year olds, and $30 \%$ for the cohort of 17-18 year olds leaving school, based on conservative extrapolation of the same data.

\section{Duration of protection}

Both vaccines have shown lasting protection against infection with HPV 16 and 18 and related disease in follow-up of up to 7.3 years for the bivalent vaccine ${ }^{31}$ or 9 years for the HPV 16 component of the quadrivalent vaccine. ${ }^{32}$ However, it is not clear whether protection will persist beyond this period. Serum antibodies for each type in the vaccine remain high 60 months or more after vaccination. ${ }^{313}$ However, a small proportion of individuals receiving the quadrivalent vaccine became seronegative to HPV 6, 11, or 18 (though not to HPV 16, and not with the bivalent vaccine ${ }^{34}$ ) by month $60 .{ }^{33}$ There were no breakthrough cases of confirmed vaccine related disease, and all vaccinated individuals showed a strong immune memory response after administration of a challenge dose at month 61 .
Hence it is unclear whether the decline in antibody titres has any clinical significance.

We considered three alternative scenarios: $(a)$ both vaccines have 20 years' average duration of protection, $(b)$ both vaccines have lifetime duration of protection, and $(c)$ both vaccines have lifetime duration of protection except for the quadrivalent vaccine against types 6,11 , and 18 , where protection lasted 20 years on average.

\section{Cross protection}

Protection against any lesion (cervical intraepithelial neoplasia grade I or greater) caused by a non-vaccine oncogenic HPV type tested for was reported as $23.4 \%$ for the quadrivalent vaccine ${ }^{10}$ and $47.7 \%$ for the bivalent vaccine. ${ }^{12}$ Differences in trial protocols and follow-up times mean it is difficult to conclusively compare efficacy estimates for the two vaccines. It is unclear whether cross protective efficacy will last, since cross neutralising antibody titres are significantly lower than type-specific titres. ${ }^{35}$

In the base case, we assumed that the bivalent and quadrivalent vaccine had $47.7 \%$ and $23.4 \%$ efficacy respectively against non-vaccine types, for the same duration as protection against vaccine types. We also considered scenarios where the duration of protection against non-vaccine types was shorter than for vaccine types. Efficacy against cervical infection and disease due to vaccine HPV types was assumed to be $100 \%$, as in our previous analyses. ${ }^{16}$ Vaccine protection against non-cervical cancers caused by non-vaccine HPV types has yet to be shown and was assumed to exist only in the optimistic scenarios (where cross protective efficacy lasts as long as efficacy against vaccine types).

The way non-vaccine oncogenic HPV types are modelled has been previously described. ${ }^{30}$ Briefly, the model structure is the same as for HPV types 16 and 18, except that all non-vaccine oncogenic types are combined into a single composite type because of lack of detailed information on individual types. However, this method has been shown to overestimate the infectivity of the composite type, and hence cause vaccine impact to be underestimated. ${ }^{36}$ To avoid this, the prevalence of the composite type was divided by 10 when we calibrated the transmission probability (a measure of the infectivity of a particular HPV type) to data; model predictions of prevalence of specific HPV types are then subsequently multiplied back up by 10 . This effectively treats the composite type as 10 separate (but identical) subtypes, against which the vaccines have $47.7 \%$ or $23.4 \%$ efficacy.

\section{Unmasking}

DNA typing studies of cervical neoplasia and cancer often find more than one high risk HPV type present in a lesion. ${ }^{17} 37$ However, with laser capture microdissection, it is possible to identify which HPV type is within the neoplastic lesion and which are in the surrounding cells. This has revealed that each neoplastic lesion contains only one high risk HPV type ${ }^{38}$ Hence, it is likely that in multiply infected women some HPV types give rise to different lesions and some HPV types are not clinically relevant, rather than multiple types contributing to the development of a single lesion. The laser capture microdissection technique is expensive and labour intensive and hence unlikely to be used for routine clinical typing or for studies with large sample sizes in the foreseeable future. Hence many studies apply algorithms such as an "oncogenic hierarchy," where, for example, a lesion with both HPV 16 and 18 DNA detected is ascribed to HPV 16 because of this type's higher 
oncogenic potential. ${ }^{39}$ Such an algorithm determines the most likely causal HPV type in a lesion, but it is unlikely to be correct all the time and will therefore underestimate the proportion of lesions (and invasive cancers) due to high risk non-vaccine HPV types that are ranked below HPV 16 and 18 in the hierarchy.

In order to correct for the underestimation of the proportion of lesions due to non-vaccine HPV types, we used an individual based cohort model fitted to data from an HPV typing study ${ }^{17}$ to determine the causal HPV types in each lesion and invasive cancer (see appendix 1 on bmj.com for details). This found increases of $10.3 \%, 5.6 \%, 6.0 \%, 5.1 \%$, and $1.2 \%$ of cervical intraepithelial neoplasia grades I, II, and III; carcinoma in situ; and cervical cancers respectively due to non-vaccine HPV types once the effect of unmasking was taken into account. ${ }^{22}$ The number of cancers diagnosed was then adjusted for the fact that a greater proportion of these are due to non-vaccine HPV types (and hence less affected by vaccination). The number of positive cytological screens and pre-cancerous lesions treated after vaccination is also affected by unmasking; however, it is not possible to estimate these differences without a full, individual based model of infection transmission, vaccination, and screening.

We did not consider the possibility of HPV type replacement (a real increase in the prevalence of non-vaccine types due to reduced competition) because there is no evidence in the virological or epidemiological literature to suggest such a phenomenon. ${ }^{40}$ Unmasking in non-cervical sites was not considered as there are no equivalent UK based studies on multiple infections in non-cervical pre-cancerous lesions and cancers.

\section{Scenarios}

Data from the vaccine trials can be interpreted in several different ways; in terms of the length of time the vaccines protect against infection with HPV types and the degree to which they prevent different end points. To accommodate these different interpretations, we have defined 12 plausible scenarios (see table $1 \Downarrow)$.

\section{Costs and quality of life weights Vaccination}

The list prices of Gardasil and Cervarix are $£ 88.50$ and $£ 80.50$ a dose respectively. ${ }^{41}$ It is likely that an HPV vaccine will be procured at a price below its list price for a UK-wide tender, but the tender price is not known. To enable comparability between equally priced bivalent and quadrivalent vaccines, we fixed the price of vaccination at $£ 84.50$ per dose (this does not affect estimates of the price difference for both vaccines to be equally cost effective). Cost of administration was based on $£ 28$ paid by the Department of Health to primary care trusts for delivering a full course of vaccination (Department of Health, personal communication).

\section{Screening}

We retained the health related quality of life states related to having a positive result from a cervical smear test or colposcopy from our previous UK analysis. ${ }^{16}$ Costs were updated to reflect the fact that England has now converted to liquid based cytology. Costs for liquid based cytology were reported as $£ 28.11$ ( 25.40 in March 2006 prices). ${ }^{42}$ Each screen was assumed to take 8.6 minutes of patient contact time with a general practitioner, ${ }^{43}$ at a cost of $£ 3$ per minute. ${ }^{24}$ Hence the total cost was estimated at $£ 54$. The cost of a colposcopy was estimated to be $£ 144$ ( $£ 130$ in March 2006 prices). ${ }^{42} 44$

\section{Warts}

The cost of treating anogenital warts was estimated in a study based in eight sexual health clinics in England and Northern Ireland to be $£ 94$ (95\% confidence interval $£ 84$ to $£ 104$ ). ${ }^{18}$ This excludes the cost of routine screening for other sexually transmitted infections; the rationale for this exclusion is that the benefits of such a screen (in terms of early diagnosis and treatment of these infections) are also ignored. When costs of treatment in general practices and tertiary care are included, the total cost rises to $£ 112$ ( $£ 104$ to $£ 120$ ). ${ }^{19}$ In the same study the mean quality of life loss per episode of warts was estimated to be 0.018 (0.0079 to 0.031$)$ quality adjusted life years (QALYs). The parameters estimated from this study are compared with those from similar studies in appendix 1 on bmj.com.

\section{Cervical cancer}

The QALY detriment associated with cervical cancer in previous studies has commonly been based on quality of life valuations derived from expert panel consensus, ${ }^{45}$ valuations from healthy individuals, ${ }^{46}$ or a survey using the Health and Limitations index (HALex) ${ }^{47}$ No studies using the EuroQol EQ-5D quality of life questionnaire in cervical cancer patients undergoing treatment could be found. Valuations from healthy women based on the "time-trade-off" method ranked stage I cervical cancer at 0.76 and stage II cervical cancer at $0.67 .{ }^{46}$ The second is close to the quality of life value of 0.68 for "female genital cancer" estimated from a survey of patients with chronic disease that made use of the HALex instrument. ${ }^{47}$

After diagnosis, prognosis was estimated based on one and five year cervical cancer survival figures from the Office for National Statistics. ${ }^{48}$ After successful treatment, health related quality of life improves. A Danish psychosocial study that followed women regularly for 24 months after radiotherapy for cervical cancer found that their satisfaction with their ability to carry out daily activities, self rated quality of life, and self rated overall physical condition steadily increased and was equal to or close to that in controls after 18 months' follow-up. ${ }^{49}{ }^{50} \mathrm{~A}$ Dutch study found a difference in EQ-5D scores of 0.061 between survivors of cervical cancer and controls. However, the difference disappeared once demographic attributes were controlled for. ${ }^{51}$

The uncertainty in these results is captured by a quality of life decrement between 0.24 and 0.33 (based on a difference of 0.67 to 0.76 from perfect health) for patients upon cancer diagnosis. They remain at this value for the duration of treatment, estimated using the mean time from the start of the first hospital spell to the end of the last hospital spell for a cervical cancer patient reported in hospital episode statistics (HES). After their final treatment, patients' quality of life improves linearly until it reaches a decrement of $0-0.061$ after 18 months. It remains there until the end of their lives.

\section{Other HPV related cancers}

Quality of life data on other HPV related cancers mostly do not fulfil criteria for the reference case used by the National Institute for Health and Clinical Excellence (NICE), ${ }^{25}$ so we had to rely on alternative sources of data. We used data from the American National Health Interview Survey (NHIS) ${ }^{47}$ for female genital cancers (used for vulval and vaginal cancer) and gastrointestinal cancers (used for anal cancer). For penile cancer, we used results from the Institute of Medicine's expert panel valuation using 
the HUI-2 instrument, ${ }^{45}$ using results for locally invasive and advanced stage cancers as two end points of a triangular distribution. For oropharyngeal cancer, we used results from a postal survey (with the EQ-5D questionnaire) of oral and oropharyngeal cancer patients after primary surgery. ${ }^{52}$

Cancer patients recovering from treatment were assumed to have the same quality of life as cervical cancer patients, although their probability of survival each year after diagnosis was assumed to be different. ${ }^{48}{ }^{53}$ Anal cancer patients (ICD (international classification of diseases) code C21) were assumed to have the same survival prospects as other anorectal cancer patients (ICD codes C19-C21), which may slightly underestimate their survival. ${ }^{54}$

While there is a good study on the cost of treatment for cervical cancer based on an audit of the Trent Cancer Registry, ${ }^{55}$ such data do not exist for other HPV related cancers. Instead, we examined three indicators of the relative cost of HPV related cancers compared with cervical cancers: $(a)$ the cost of hospital spells in the HES database with operative procedures for HPV related cancers, with the costing done by linking them to the corresponding health related diagnosis (HRG) code using the HRG4 2008-9 Reference Cost Grouper (www.ic.nhs.uk/ services/the-casemix-service/using-this-service/reference/ downloads/costing), (b) the ratio of the annual number of hospital spells for each cancer type to the annual number of cases of cancer registered by the Office for National Statistics in 2007 (to estimate the average number of hospital spells per cancer case), and (c) the direct medical costs of HPV related cancers in the US, estimated in another study using secondary data. $^{56}$

The three methods give separate estimates of the relative costs of treating different kinds of cancer. Cervical cancer costs from the previous audit ${ }^{55}$ were used, with cancer staging based on a Dutch study.$^{57}$ In 2009 prices, this gave a cost of $£ 15000$ per cancer case. The relative cost of each non-cervical cancer compared with cervical cancer, based on each of the three methods, was then used to multiply the cost of cervical cancer. Actual costs were then sampled from a triangular distribution with end points at the smallest and largest of the three estimates, and vertex at their geometric mean.

\section{Recurrent respiratory papillomatoses}

The QALY loss accrued to a patient with recurrent respiratory papillomatosis was based on a lognormal distribution fitted to a QALY loss of 1.3 (range 0.029-5.28), based on an estimated loss of $0.31(0.1-0.96)$ QALYs per year of the disease and disease length of $4.2(2.9-5.5)$ years in a US study. ${ }^{58} \mathrm{~A}$ recent Canadian study estimated that the health utility of children with recurrent respiratory papillomatoses is about 0.75 (based on a visual analogue scale) to 0.76 (based on the HUI- 3 instrument). ${ }^{59}$ The quality of life decrement from perfect health is quite close to the estimated annual QALY loss in the US study. A Finnish case-control study suggested that children with recurrent respiratory papillomatoses may continue to have a lower quality of life in adulthood compared with matched controls. ${ }^{60}$ This was not incorporated here as the difference was small, and it was not clear whether it might be due to residual confounding (subjects were matched for age, sex, and smoking status only). Treatment costs were estimated at $£ 4900$ per adult and $£ 30000$ per child. ${ }^{20}$ Any deaths due to juvenile onset recurrent respiratory papillomatoses were assumed to occur at an average age of 4 years. ${ }^{61}$

\section{Sensitivity analysis}

Uncertainty in results was captured by drawing 10000 samples from combinations of (a) 2700 previously described scenarios for oncogenic HPV types ${ }^{30}$ and 900 scenarios for HPV types 6 and 11 representing combinations of assumptions about the natural course and epidemiology of HPV infection, and $(b)$ probability distributions representing uncertainty in economic parameters (with sampling distributions shown in table $2 \Downarrow$ ). Sampling from both sets was conducted using the Latin hypercube method. For economic parameters, normal, lognormal, or beta distributions were assumed when quantitative data about the uncertainty around parameters were available. If they were not, triangular distributions based around several point estimates were assumed. When only a single point estimate was available, a normal distribution with coefficient of variation 0.25 was assumed.

\section{Price difference}

The price difference between equally cost effective bivalent and quadrivalent vaccines was estimated by calculating the difference between the net present values of the two vaccines (monetary value in 2008-9 of all the cost savings and QALYs gained over the 100 years of the model), divided by the number of doses needed to achieve these benefits.

\section{Results \\ Effect on disease}

Use of either vaccine is expected to substantially decrease the incidence of HPV related cancers regardless of which scenario is assumed (see fig $1 \Downarrow$ ). The benefit is greater when duration of protection is assumed to be lifelong. By 2109 , use of the quadrivalent vaccine may be preventing a median of 700 (interquartile range 630-800) to 1000 (940-1100) cervical cancer cases a year (depending on scenario), and the bivalent vaccine about $730(650-830)$ to $1100(990-1200)$ cases. The interquartile range is the difference across Monte Carlo samples within the same scenario. The difference between the quadrivalent and bivalent vaccine is not great, despite potentially greater cross protection from the bivalent vaccine. This is true even in scenarios where the quadrivalent vaccine has a shorter duration of protection against HPV 18 (scenarios 3 and 6), since most cervical cancers are related to HPV 16.

In addition, by 2109 vaccination may prevent about 620 (560-720) to 950 (900-1000) non-cervical cancer cases annually. Even if vaccination protects only against end points indicated in the vaccines' licensure, quadrivalent vaccination may prevent 430 (380-490) to 630 (950-670) vulval, vaginal, and anal cancers a year by 2109 . Use of the quadrivalent vaccine is expected to decrease the incidence of vaccine type warts and recurrent respiratory papillomatoses by up to $95 \%$ if duration of protection is lifelong. However, the bivalent vaccine is likely to be more effective in preventing death due to cancer. It may prevent $1.1 \%(1.0-1.3 \%)$ to $4.1 \%$ (3.4-4.8\%) more deaths due to cancer if both vaccines protect against all HPV related cancer end points.

\section{Economic benefit}

The most important benefit of either vaccine in terms of reducing healthcare costs and lost QALYs due to disease is in protecting against cervical cancer and its precursor lesions (see fig $2 \Downarrow$ ). Protection against anogenital warts is also an important additional benefit of the quadrivalent vaccine, because of their high incidence and the proximity of their occurrence to the time 
of vaccination. Possible protection against non-cervical cancers, while a substantial benefit, is less important in economic (cost and quality of life) terms compared with cervical cancer protection.

\section{Cost effectiveness}

The quadrivalent vaccine seems to be cost effective at a threshold of $£ 30000$ per QALY gained across all 12 of the scenarios considered (see fig $3 \Downarrow$ ). The incremental cost effectiveness ratio of quadrivalent vaccination (compared with no vaccination) ranges from $£ 12000(£ 11000-£ 14000)$ to $£ 19$ 000 ( $£ 17$ 000-£22 000) when protection against anal, penile, and oropharyngeal cancers is assumed, and up to $£ 22000$ ( $£ 19$ 000-£25 000) when only protection against licensed end points is assumed. The incremental cost effectiveness ratio of bivalent vaccination (compared with no vaccination) ranges from $£ 16$ 000 ( 14 000-£18 000) to $£ 25000$ ( $221000-£ 28000$ ) with protection against all cancer end points, and up to $£ 41000$ ( $£ 34$ 000-£45 000) with protection against licensed end points only. Hence when making pessimistic assumptions about duration of protection and range of end points prevented, bivalent vaccination may not be cost effective at $£ 84.50$ per dose.

\section{Additional cost per dose of the quadrivalent vaccine}

If QALYs are valued at $£ 30000$ each, then the additional cost per dose (for a three dose course) of the quadrivalent vaccine for it to be equally cost effective as the bivalent vaccine ranges from $£ 19$ ( $£ 12-£ 27$ ) to $£ 38$ ( $£ 30-£ 47$ ) if both vaccines protect against all HPV related cancer end points (see fig $4 \Downarrow$ ). If the vaccines are assumed to protect only against cancer end points in their licensure, then the differential between threshold costs per dose for the two vaccines is greater (median $£ 48$ to $£ 68$ across scenarios), due to protection against vulvar, vaginal, and anal cancers being a benefit of quadrivalent vaccination only. If QALYs are valued at only $£ 20000$ each, the differential is smaller (median $£ 14$ to $£ 28$, or $£ 35$ to $£ 48$ if only licensed end points are protected against).

The quadrivalent vaccine's protection against anogenital warts seems more important than possible advantages of the bivalent vaccine in terms of cervical cancer prevention, when measured in terms of QALYs gained and costs prevented (fig $5 \Downarrow$ ). However, the bivalent vaccine may have an advantage in preventing death due to cancer.

\section{Effect of lower discounting of benefits}

If the rate at which benefits are discounted is reduced to $1.5 \%$ per annum, then the additional cost of an equally cost effective quadrivalent vaccine increases to between $£ 36(£ 21-£ 53)$ and $£ 157$ (£134-£178) per dose, depending on the strategy, when a QALY is valued at $£ 30000$. The uncertainty around the estimates also increases, since this gives greater weight to outcomes further in the future for which model predictions are less certain. Note that a lower discount rate increases the present value of the benefits of both cancer and warts prevention, but the benefits of cancer prevention increase proportionately by more, since they occur later in the future. However, the size of the contribution to the vaccine cost difference from warts prevention by the quadrivalent vaccine is much greater than that of additional protection against cancer by the bivalent vaccine in all the scenarios. Hence, overall reduction of the discount rate favours the quadrivalent vaccine.

\section{Discussion Principal findings}

In our previous analysis in 2008 to inform vaccine procurement for the UK HPV immunisation programme, the median additional price per dose for an equally cost effective quadrivalent vaccine was estimated to be about $£ 15$ per dose (for a vaccine with lifetime duration) to $£ 23$ per dose (for a vaccine with 20 years duration). ${ }^{16}$ The estimates in most of the scenarios presented here are greater than this for several reasons. Firstly, the quadrivalent vaccine has now shown protection against precursors to vulvar, vaginal, and anal cancer in clinical trials, but the bivalent vaccine had not at the time the analysis was conducted (more recently it has been shown to protect against anal infection). If we assume that the two vaccines protect against the same HPV 16 and 18 related end points (which seems reasonable), the price differential narrows but is still greater than in our 2008 analysis. This is because the estimate of the quality of life detriment due to an episode of warts has increased, based on the results of a new study on the burden of anogenital warts. ${ }^{18}$ In particular, the study explicitly asked respondents how long they had warts before seeking care; in some cases respondents reported waiting for years before they did.

Protection against HPV 6 and 11 related low grade lesions and recurrent respiratory papillomatoses, while incremental benefits of quadrivalent vaccination, does not have a large effect on the cost differential.

Only when the scenario most favourable to bivalent vaccination is assumed (both vaccines protect against the same HPV 16 and 18 end points, but the bivalent vaccine has a longer duration of protection against HPV 18 and long lasting protection against non-vaccine types) does the additional price per dose of an equally cost effective quadrivalent vaccine drop below the estimate in our previous analysis.

However, if the object of HPV vaccination is solely cancer prevention, then the bivalent vaccine is likely to prevent more cancers and cancer deaths than the quadrivalent vaccine.

\section{Comparison with other studies}

The choice between the two currently licensed HPV vaccines has been subject to intense debate in countries such as Australia and the UK with central vaccine procurement. ${ }^{62-66}$ Yet few published studies have tried to estimate the price difference for the two vaccines to be equally cost effective.

An Irish study ${ }^{67}$ found that the bivalent vaccine would have to be $22 \%$ (or about $€ 20$ a dose) cheaper to be equally cost effective as the quadrivalent vaccine because of lack of protection against anogenital warts, assuming lifelong vaccine duration. A Canadian study ${ }^{68}$ suggested that the difference should be about $\mathrm{C} \$ 35$ a dose. Both were static models and hence did not take into account indirect protection, nor did they assess potential differences between the vaccines in terms of licensure end points (besides warts), cross protection, or duration of protection. In addition, other papers have estimated the effect on cost effectiveness of particular features of one or both vaccines, such as warts protection, ${ }^{69}$ impact on non-cervical cancers, ${ }^{70}$ cross protection, and duration of protection. ${ }^{71}$

Our analysis is the first to integrate all these potential benefits that may differentiate one vaccine over another into a single analysis and to present price differentials per dose for a range of scenarios in a way that can be immediately used for deciding which vaccine to use in central procurement. 


\section{Limitations}

There are several limitations to this analysis. Firstly, HPV vaccine manufacturers have sought to differentiate their vaccines from each other based on their composition (valency and adjuvants), end points prevented, long term immunogenicity, and protection against HPV types not included in the vaccine. However, in some cases it is not clear to what extent these differences affect clinical efficiency at the population level. For instance, immunogenicity may not be a reliable marker of clinical protection, cross protective efficacy may not prove to be long lasting, and the lack of evidence for the protective effect of bivalent vaccination on non-cervical end points may simply reflect the failure of its manufacturers to investigate such effects. Furthermore, reported cross protective efficacy against neoplasia may not be accurate as it involves having to determine the causal HPV type when there is more than one type present.

Consequently, we have developed a range of scenarios representing different interpretations of trial data. These scenarios are not equally likely: for example, it seems more plausible that both vaccines can prevent all HPV related cancer end points (scenarios 7-12) than simply the end points in their indication (scenarios 1-6). As long term efficacy and population level efficiency data become available, some of these scenarios may seem unrealistic. However, given our present knowledge, our models suggest that the range in estimated price differences across the scenarios is large.

Secondly, only poor data are available on the natural course of HPV related cancers in sites other than the cervix, even though these account for a substantial portion of the burden of HPV infection that is potentially preventable by vaccination. Hence we did not realistically model the natural course of these cancers, but instead imputed the age dependent reduction seen in cervical cancers caused by vaccine HPV type infection. We had to assume that the proportion of each cancer type attributable to HPV is not age dependent, although there is evidence that this may not be true for some cancers. ${ }^{2}$ In some cases (such as oropharyngeal cancers) there is no consensus among epidemiologists about the proportion of cancers caused by HPV. The incidence of oropharyngeal cancers attributable to HPV seems to be increasing in many countries for reasons that are not fully understood, but we decided not to incorporate this apparent increase as it is not yet clear whether this trend will continue. Also, our method may overestimate the potential reduction in male cancers, since a substantial proportion of them occur in men who have sex with men (particularly for anal cancer), who are currently not routinely vaccinated and who may benefit less from herd immunity than heterosexual men.

Thirdly, because of data and model limitations, we have represented non-vaccine HPV types as a single composite type. To avoid overestimating the transmission probability of the composite type, ${ }^{36}$ we have effectively treated this HPV type as 10 separate (but identical) subtypes. However, this correction is an approximation, since the transmission probability and vaccine efficacy against each of these subtypes is different.

Lastly, we have assumed that quadrivalent vaccination reduces the incidence of recurrent respiratory papillomatoses at the same rate as that of warts related to HPV 6 and 11. This assumption is valid only if the delay between maternal HPV 6 and 11 infection and development of juvenile onset recurrent respiratory papillomatosis is similar to the delay between HPV 6 and 11 infection and warts diagnosis. There is little information in the literature to inform such an assumption, but we may have slightly overestimated the speed of reduction of recurrent respiratory papillomatoses given that they can occur in young children some years after birth.

\section{Conclusions and implications}

In conclusion, our analysis shows that considerable uncertainty remains about the differential benefit of the two available HPV vaccines in terms of their efficacy against non-vaccine HPV types; prevention of non-cervical cancer, warts, and recurrent respiratory papillomatoses; and duration of protection. Clinical and public health decisions about choice of HPV vaccine need to take account of the whole spectrum of differences between vaccines and the uncertainty around them. Based on recent evidence, the price differential between the quadrivalent and bivalent vaccine for both to be equally cost effective seems to be larger than in our previous analysis, ${ }^{16}$ unless assumptions most favourable to bivalent vaccination are assumed.

We thank Sarika Desai and Colin Campbell for conducting the analyses on the costs of cancer, Sarika Desai and Sarah Woodhall for providing results of the burden of anogenital warts, Kate Soldan and Peter White for many helpful comments, Alan Sheridan and Joanne White for information on HPV vaccine coverage, June Boggis and Stephen Robinson for information about the cost of vaccine delivery in the UK, members of the BAPO-ENT-UK survey team (individual names listed in Hughes et $\mathrm{al}^{20}$ ) for information on the burden of recurrent respiratory papillomatoses, and Joakim Dillner for helpful discussions about HPV type distribution in anogenital warts.

Contributors: MJ designed the study; MJ, YHC, and RC carried out the computer simulations and analysis; $\mathrm{OH}$ carried out the survey of recurrent respiratory papillomatoses and analysed the results; RC reviewed the literature on non-cervical cancers; MJ drafted the manuscript with input from the other authors; all authors approved the final version to be published. $M J$ is the guarantor.

Funding: RC was funded by a grant from the Policy Research Programme of the Department of Health, England (reference DOH 039/0031). OH was funded by a Medical Research Council Clinical Research Training Fellowship (reference G0900348). The authors' work was independent of the funders, who had no role in the study design, analysis of data, writing of the manuscript, or decision to submit for publication.

\section{Sponsorship: None}

All authors have completed the ICMJE uniform disclosure form at www. icmje.org/coi_disclosure.pdf (available on request from the corresponding author). $\mathrm{OH}$ has received unrestricted funding from Sanofi Pasteur to investigate the potential benefits of the quadrivalent $L 1$ vaccine as therapy for recurrent respiratory papillomatoses. The other authors declare no support from any organisation for the submitted work; no financial relationships with any organisations that might have an interest in the submitted work in the previous three years; no other relationships or activities that could appear to have influenced the submitted work.

Ethical approval: Not required

Data sharing: No additional data available.

1 Bosch FX, Lorincz A, Munoz N, Meijer CJ, Shah KV. The causal relation between human papillomavirus and cervical cancer. J Clin Pathol 2002;55:244-65.

2 Parkin DM, Bray F. Chapter 2: The burden of HPV-related cancers. Vaccine 2006;24 (suppl 3):S3-11-S3/25.

3 Clifford, G. The growing evidence of an epidemiological link between oral cancers and Clifford, G. The growing evidence of an epidemiological link between oral
HPV. Presented at EUROGIN 2010, Monte Carlo, Monaco, Feb 20, 2010.

4 Bosch FX, de Sanjose S. Chapter 1: Human papillomavirus and cervical cancer-burden and assessment of causality. J Nat/ Cancer Inst Monogr 2003;3-13.

5 Dillner J, Kjaer SK, Wheeler CM, Sigurdsson K, Iversen OE, Hernandez-Avila M, et al. Four year efficacy of prophylactic human papillomavirus quadrivalent vaccine against low grade cervical, vulvar, and vaginal intraepithelial neoplasia and anogenital warts: randomised controlled trial. BMJ 2010;341:c3493.

6 Gissmann L, Diehl V, Schultz-Coulon HJ, zur HH. Molecular cloning and characterization of human papilloma virus DNA derived from a laryngeal papilloma. J Virol 1982;44:393-400. Joura EA, Leodolter S, Hernandez-Avila M, Wheeler CM, Perez G, Koutsky LA, et al. Efficacy of a quadrivalent prophylactic human papillomavirus (types 6, 11, 16, and 18) 


\section{What is already known on this topic}

The two licensed HPV vaccines both protect against HPV types 16 and 18 (which cause most cases of cervical cancer) but differ in terms of licensure indications, protection against disease related to non-vaccine oncogenic HPV types, protection against disease related to HPV types 6 and 11, reported long term immunogenicity, and price per dose No economic evaluation has considered all the potential differences between the two vaccines within the same model

\section{What this study adds}

Even when possible longer duration of protection and better cross protection against non-vaccine HPV types of the bivalent vaccine is taken into consideration, the quadrivalent vaccine is still more cost effective if the two are equally priced

L1 virus-like-particle vaccine against high-grade vulval and vaginal lesions: a combined analysis of three randomised clinical trials. Lancet 2007;369:1693-702.

8 Giuliano AR, Palefsky JM, Goldstone S, Moreira ED, Penny ME, Aranda C, et al. Efficacy of quadrivalent HPV vaccine against HPV infection and disease in males. $N$ Engl $\mathrm{J} \mathrm{Med}$ 2011;364:401-11

9 Kreimer AR, González P, Katki HA, Porras C, Schiffman M, Rodriguez AC, et al. Efficacy of a bivalent HPV 16/18 vaccine against anal HPV 16/18 infection among young women: a nested analysis within the Costa Rica Vaccine Trial. Lancet Oncol 2011;12:862-70.

10 Brown DR, Kjaer SK, Sigurdsson K, Iversen OE, Hernandez-Avila M, Wheeler CM, et al. The impact of quadrivalent human papillomavirus (HPV; types 6, 11, 16, and 18) L1 virus-like particle vaccine on infection and disease due to oncogenic nonvaccine HPV types in generally HPV-naive women aged 16-26 years. J Infect Dis 2009;199:926-35.

11 Paavonen J, Naud P, Salmeron J, Wheeler CM, Chow SN, Apter D, et al. Efficacy of human papillomavirus (HPV)-16/18 AS04-adjuvanted vaccine against cervical infection and precancer caused by oncogenic HPV types (PATRICIA): final analysis of a double-blind, randomised study in young women. Lancet 2009;374:301-14.

12 Tjalma W, Paavonen J, Naud P, Wheeler C, Chow S-N, Apter D, et al. Efficacy of the HPV-16/18 AS04-adjuvanted vaccine against abnormal cytology and low-grade histopathological lesions in an oncogenic HPV-naive population. Presentation at the 16th International Meeting of the European Society for Gynaecological Oncology, Belgrade, October 11-14, 2009. Int J Gynecol Cancer 2009;19:1-1024.

13 Romanowski B. Long term protection against cervical infection with the human papillomavirus: Review of currently available vaccines. Hum Vaccin 2011;7(2) [epub ahead of print].

14 Kim JJ. Human papillomavirus vaccination in the UK. BMJ 2008:337:a842.

15 Sheridan A, White J. Annual HPV vaccine coverage in England in 2009/2010. Report commissioned by the Department of Health. www.dh.gov.uk/prod_consum_dh/groups/ dh_digitalassets/documents/digitalasset/dh_123826.pdf.

16 Jit M, Choi YH, Edmunds WJ. Economic evaluation of human papillomavirus vaccination in the United Kingdom. BMJ 2008:337:a769.

17 Howell-Jones R, Bailey A, Beddows S, Sargent A, de Silva N, Wilson G, et al. Multi-site study of HPV type-specific prevalence in women with cervical cancer, intraepithelial neoplasia and normal cytology, in England. Br J Cancer 2010;103:209-16.

18 Woodhall SC, Jit M, Soldan K, Kinghorn G, Gilson R, Nathan M, et al. The impact of genital warts: loss of quality of life and cost of treatment in eight sexual health clinics in the UK. Sex Transm Infect 2011 [epub ahead of print].

19 Desai S, Wetten S, Woodhall SC, Peters L, Hughes G, Soldan K. Genital warts and the cost of care in England. Sex Transm Inf [forthcoming].

20 Hughes OR, Tsikoudas A, Auerbach R, Barr GD, Bateman N, Blarney S, et al. The burden of recurrent respiratory papillomatosis in the United Kingdom: results from the BAPO and ENT-UK National Survey. Clin Otolaryngol [forthcoming].

21 Chapman R, Soldan K, Jit M. Modelling borderline and mild dysplasia associated with HPV 6 and 11 infection. Vaccine 2011:29:2881-6.

22 Choi Y, Jit M, Gay N. Unmasking HPV genotypes as impact of HPV vaccination. Poster P-29.44 presented at the International Papillomavirus Conference, Malmo, Sweden, May 8-14, 2009.

23 Department of Health. Key vaccine information: HPV . www.dh.gov.uk/en/Publichealth/ Immunisation/Keyvaccineinformation/DH_104010

24 Curtis L. Unit costs of health and social care 2009. Personal Social Services Research Unit, University of Kent, 2009.

25 National Institute for Health and Clinical Excellence. Guide to the methods of technology appraisal . NICE, 2008.

26 Office for National Statistics. Cancer statistics 2007: registrations series MB1 No 37. www.statistics.gov.uk/downloads/theme health/MB1-38/Table_1.xls.

27 Greer CE, Wheeler CM, Ladner MB, Beutner K, Coyne MY, Liang H, et al. Human papillomavirus (HPV) type distribution and serological response to HPV type 6 virus-like particles in patients with genital warts. J Clin Microbiol 1995;33:2058-63.

28 Brown DR, Schroeder JM, Bryan JT, Stoler MH, Fife KH. Detection of multiple human papillomavirus types in Condylomata acuminata lesions from otherwise healthy and immunosuppressed patients. J Clin Microbiol 1999;37:3316-22.

29 Sturegard E, Johnsson A, Gustafsson E, Dillner J. [Condyloma typing important for follow up of HPV vaccination. A condyloma reporting project.] Lakartidningen 2008;105:3648-50.

30 Choi YH, Jit M, Gay N, Cox A, Garnett GP, Edmunds WJ. Transmission dynamic modelling of the impact of human papillomavirus vaccination in the United Kingdom. Vaccine 2010;28:4091-102.

31 De Carvalho N, Teixeira J, Roteli-Martins CM, Naud P, De Borba P, Zahaf T, et al . Sustained efficacy and immunogenicity of the HPV-16/18 AS04-adjuvanted vaccine up to 7.3 years in young adult women. Vaccine 2010;28:6247-55

32 Steben M. Update on Gardasil (quadrivalent human papillomavirus [HPV] 6/11/16/18 vaccine) clinical trial efficacy results. Presented at EUROGIN 2010, Monte Carlo, Monaco, Feb 17-20, 2010

33 Olsson SE, Villa LL, Costa RL, Petta CA, Andrade RP, Malm C, et al. Induction of immune memory following administration of a prophylactic quadrivalent human papillomavirus (HPV) types 6/11/16/18 L1 virus-like particle (VLP) vaccine. Vaccine 2007;25:4931-9.

34 David MP, Van Herck K, Hardt K, Tibaldi F, Dubin G, Descamps D, et al. Long-term persistence of anti-HPV-16 and -18 antibodies induced by vaccination with the
AS04-adjuvanted cervical cancer vaccine: modeling of sustained antibody responses. Gynecol Oncol 2009; 115:S1-6

35 Schiller JT, Castellsague X, Villa LL, Hildesheim A. An update of prophylactic human papillomavirus L1 virus-like particle vaccine clinical trial results. Vaccine 2008;26 (suppl 10):K53-61.

36 Van de Velde N, Brisson M, Boily MC. Understanding differences in predictions of HPV vaccine effectiveness: A comparative model-based analysis. Vaccine 2010;28:5473-84.

37 Kitchener HC, Almonte M, Wheeler P, Desai M, Gilham C, Bailey A, et al. HPV testing in routine cervical screening: cross sectional data from the ARTISTIC trial. Br J Cancer 2006;95:56-61.

38 Quint W, Molijn A, Colau B, van de Sandt M, Jenkins D. One HPV virus, one lesion as determined by LCM/PCR technology. Abstract 06.04. 25th International Papillomavirus Conference, Malmo, Sweden, 2009.

39 Wheeler CM, Hunt WC, Joste NE, Key CR, Quint WG, Castle PE. Human papillomavirus genotype distributions: implications for vaccination and cancer screening in the United States. J Natl Cancer Inst 2009;101:475-87.

40 Franco $E$. Is type replacement something to worry about: yes or no? Oral presentation at EUROGIN 2010, Monte Carlo, Monaco, Feb 17-20, 2010.

41 British Medical Association and the Royal Pharmaceutical Society of Great Britain. British National Formulary 59. BMA, 2010

42 Martin-Hirsch P, Rash B, Martin A, Standaert B. Management of women with abnormal cervical cytology: treatment patterns and associated costs in England and Wales. BJOG 2007;114:408-15.

43 Karnon J, Peters J, Platt J, Chilcott J, McGoogan E, Brewer N. Liquid-based cytology in cervical screening: an updated rapid and systematic review and economic analysis. Health Technol Assess 2004;8(20):iii, 1-78.

44 Brown RE, Breugelmans JG, Theodoratou D, Benard S. Costs of detection and treatment of cervical cancer, cervical dysplasia and genital warts in the UK. Curr Med Res Opin 2006;22:663-70.

45 Institute of Medicine. Vaccines for the 21st century: a tool for decisionmaking. National Academy Press, 2000.

46 Myers ER, Green S, Lipkus I. Patient preferences for health states related to HPV infection: visual analog scales vs time trade-off elicitation. 21st International Papillomavirus Conference and Clinical Workshop, Mexico City, Mexico.

47 Gold MR, Franks P, McCoy KI, Fryback DG. Toward consistency in cost-utility analyses: using national measures to create condition-specific values. Med Care 1998;36:778-92.

48 Office for National Statistics. Cancer survival, England, patients diagnose 2001-2006 and followed up to 2007: one-year and five-year relative survival for 21 common cancers, by sex and age. www.statistics.gov.uk/downloads/theme_health/cancer-survival-Eng-2001 2006.pdf.

49 Klee M, Thranov I, Machin D. Life after radiotherapy: the psychological and social effects experienced by women treated for advanced stages of cervical cancer. Gynecol Oncol 2000;76:5-13.

50 Klee M, Thranov I, Machin PD. The patients' perspective on physical symptoms after radiotherapy for cervical cancer. Gynecol Oncol 2000;76:14-23.

51 Korfage IJ, Essink-Bot ML, Mols F, Poll-Franse L, Kruitwagen R, van Ballegooijen M. Health-related quality of life in cervical cancer survivors: a population-based survey. Int J Radiat Oncol Biol Phys 2009;73:1501-9.

52 Rogers SN, Miller RD, Ali K, Minhas AB, Williams HF, Lowe D. Patients' perceived health status following primary surgery for oral and oropharyngeal cancer. Int $\mathrm{J}$ Oral Maxillofac Surg 2006;35:913-9.

53 Office for National Statistics. One- and five-year surival of patients diagnosed in 1991-95 and 1996-99: less common cancers, sex and age, England and Wales . www.statistics. gov.uk/statbase/Expodata/Spreadsheets/D8904.xls.

54 Jeffreys M, Rachet B, McDowell S, Habib AG, Lepage C, Coleman MP. Survival from rectal and anal cancers in England and Wales, 1986-2001. Eur J Cancer 2006;42:1434-40.

55 Wolstenholme JL,Whynes DK. Stage-specific treatment costs for cervical cancer in the United Kingdom. Eur J Cancer 1998;34:1889-93.

$56 \mathrm{Hu}$ D, Goldie S. The economic burden of noncervical human papillomavirus disease in the United States. Am J Obstet Gynecol 2008;198:500-7.

57 De Rijke JM, van der Putten HW, Lutgens LC, Voogd AC, Kruitwagen RF, van Dijck JA et al. Age-specific differences in treatment and survival of patients with cervical cancer in the southeast of the Netherlands, 1986-1996. Eur J Cancer 2002;38:2041-7.

58 Bishai D, Kashima H, Shah $\mathrm{K}$. The cost of juvenile-onset recurrent respiratory papillomatosis. Arch Otolaryngol Head Neck Surg 2000;126:935-9.

59 Chadha NK, Allegro J, Barton M, Hawkes M, Harlock H, Campisi P. The quality of life and health utility burden of recurrent respiratory papillomatosis in children. Otolaryngol Head Neck Surg 2010;143:685-90.

60 Ilmarinen T, Nissila H, Rihkanen H, Roine RP, Pietarinen-Runtti P, Pitkaranta A, et al. Clinical features, health-related quality of life, and adult voice in juvenile-onset recurrent respiratory papillomatosis. Laryngoscope 2011;121:846-51.

61 Reeves WC, Ruparelia SS, Swanson KI, Derkay CS, Marcus A, Unger ER. National registry for juvenile-onset recurrent respiratory papillomatosis. Arch Otolaryngol Head Neck Surg 2003;129:976-82.

62 Stern PL. For debate: that Australia should consider changing to the bivalent vaccine. Sex Health 2010;7:238-41. 
63 Wain G. For debate: that Australia should continue using the quadrivalent vaccine. Sex Health 2010;7:235-7.

64 Morris SR. HPV vaccine strategies: the cost of HPV and the choice of vaccine. Sex Transm Infect 2009;85:315-6.

65 Hawkes N. Anger over Department of Health choice of cheaper cancer vaccine. Times 2008 July 18.

66 Haas M, Ashton T, Blum K, Christiansen T, Conis E, Crivelli L, et al. Drugs, sex, money and power: an HPV vaccine case study. Health Policy 2009;92:288-95.

67 Dee A, Howell F. A cost-utility analysis of adding a bivalent or quadrivalent HPV vaccine to the Irish cervical screening programme. Eur J Public Health 2010;20:213-9.

68 Brisson M, Van de Velde N, De Wals P, Boily MC. The potential cost-effectiveness of prophylactic human papillomavirus vaccines in Canada. Vaccine 2007;25:5399-408.

$69 \mathrm{Kim} \mathrm{JJ}$, Goldie SJ. Health and economic implications of HPV vaccination in the United States. N Engl J Med 2008;359:821-32.
70 De Kok IM, Habbema JD, van Rosmalen J, van Ballegooijen M. Would the effect of HPV vaccination on non-cervical HPV-positive cancers make the difference for its cost-effectiveness? Eur J Cancer 2011;47:428-35.

71 Demarteau N, Standaert B. Modelling the economic value of cross- and sustained-protection in vaccines against cervical cancer. J Med Econ 2010;13:324-38.

Accepted: 26 August 2011

\section{Cite this as: BMJ 2011:343:d5775}

This is an open-access article distributed under the terms of the Creative Commons Attribution Non-commercial License, which permits use, distribution, and reproduction in any medium, provided the original work is properly cited, the use is non commercial and is otherwise in compliance with the license. See: http://creativecommons.org/licenses/bync/2.0/ and http://creativecommons.org/licenses/by-nc/2.0/legalcode. 


\section{Tables}

Table 1/ Plausible scenarios about the duration of vaccine protection and end points that the vaccines may protect against, as used in the economic modelling comparing bivalent and quadrivalent human papillomavirus (HPV) vaccines

\begin{tabular}{|c|c|c|c|c|c|c|c|}
\hline \multirow[b]{3}{*}{ Scenario } & \multicolumn{3}{|c|}{ Bivalent } & \multicolumn{4}{|c|}{ Quadrivalent } \\
\hline & \multicolumn{2}{|c|}{ Duration of protection } & \multirow{2}{*}{$\begin{array}{c}\text { Cancer end } \\
\text { points } \\
\text { prevented }\end{array}$} & \multicolumn{2}{|c|}{ Duration of protection } & \multirow{2}{*}{$\begin{array}{c}\text { Cancer end } \\
\text { points } \\
\text { prevented }\end{array}$} & \multirow{2}{*}{$\begin{array}{l}\text { HPV } 6 \text { or } 11 \\
\text { end points } \\
\text { prevented }\end{array}$} \\
\hline & Vaccine HPV types* & $\begin{array}{c}\text { Non-vaccine HPV } \\
\text { types }\end{array}$ & & Vaccine HPV types* & $\begin{array}{c}\text { Non-vaccine HPV } \\
\text { types }\end{array}$ & & \\
\hline 1 & 20 years & 20 years & \multirow{6}{*}{$\begin{array}{l}\text { Cervical (all } \\
\text { HPV types) }\end{array}$} & 20 years & 20 years & \multirow{3}{*}{$\begin{array}{c}\text { Cervical, } \\
\text { vaginal, vulvar, } \\
\text { anal (all HPV } \\
\text { types) }\end{array}$} & \multirow{6}{*}{$\begin{array}{l}\text { Warts, mild } \\
\text { smears }\end{array}$} \\
\hline 2 & Lifetime & Lifetime & & Lifetime & Lifetime & & \\
\hline 3 & Lifetime & Lifetime & & $\begin{array}{c}\text { Lifetime (HPV 16), } 20 \\
\text { years (others) }\end{array}$ & Lifetime & & \\
\hline 4 & 20 years & 10 years & & 20 years & 10 years & \multirow{3}{*}{$\begin{array}{l}\text { Cervical (all } \\
\text { HPV types), } \\
\text { vaginal, vulvar, } \\
\text { anal (vaccine } \\
\text { HPV types } \\
\text { only) }\end{array}$} & \\
\hline 5 & Lifetime & 20 years & & Lifetime & 20 years & & \\
\hline 6 & Lifetime & 20 years & & $\begin{array}{c}\text { Lifetime (HPV 16), } 20 \\
\text { years (others) }\end{array}$ & 20 years & & \\
\hline 7 & 20 years & 20 years & \multirow{3}{*}{$\begin{array}{l}\text { All (all HPV } \\
\text { types) }\end{array}$} & 20 years & 20 years & \multirow{3}{*}{$\begin{array}{l}\text { All (all HPV } \\
\text { types) }\end{array}$} & \multirow{3}{*}{$\begin{array}{l}\text { Warts, mild } \\
\text { smears, } \\
\text { recurrent } \\
\text { respiratory } \\
\text { papillomatoses }\end{array}$} \\
\hline 8 & Lifetime & Lifetime & & Lifetime & Lifetime & & \\
\hline 9 & Lifetime & Lifetime & & $\begin{array}{c}\text { Lifetime (HPV 16), } 20 \\
\text { years (others) }\end{array}$ & Lifetime & & \\
\hline 10 & 20 years & 10 years & \multirow{3}{*}{$\begin{array}{l}\text { Cervical (all } \\
\text { HPV types), } \\
\text { all others } \\
\text { (vaccine } \\
\text { HPV types } \\
\text { only) }\end{array}$} & 20 years & 10 years & \multirow{3}{*}{$\begin{array}{l}\text { Cervical (all } \\
\text { HPV types), all } \\
\text { others (vaccine } \\
\text { HPV types } \\
\text { only) }\end{array}$} & \\
\hline 11 & Lifetime & 20 years & & Lifetime & 20 years & & \\
\hline 12 & Lifetime & 20 years & & $\begin{array}{c}\text { Lifetime (HPV 16), } 20 \\
\text { years (others) }\end{array}$ & 20 years & & \\
\hline
\end{tabular}


Table 2| Parameters used in the economic modelling comparing bivalent and quadrivalent human papillomavirus (HPV) vaccines, and their sampling distribution for the probabilistic sensitivity analysis

\begin{tabular}{|c|c|c|c|}
\hline Parameter & Mean & Distribution & Source \\
\hline \multicolumn{4}{|l|}{ Other parameters } \\
\hline \multicolumn{4}{|l|}{ Costs } \\
\hline Treatment for cervical cancer & $£ 15000$ & Lognormal mean 15000 (SD 9300) & Wolstenholme et $\mathrm{al}^{55} ;$ De Rijke et $\mathrm{al}^{57}$ \\
\hline \multicolumn{4}{|l|}{ Relative cost of treatment ( $v$ cervical cancer): } \\
\hline Vulvar and vaginal cancer & 0.91 & Triangular $(\min 0.65, \max 1.3$, mode 0.75$)$ & \multirow[t]{4}{*}{ Hu et $\mathrm{al}^{56}$; hospital and cancer registry data } \\
\hline Anal cancer & 0.87 & Triangular $(\min 0.48, \max 1.5$, mode 0.64$)$ & \\
\hline Oropharyngeal cancer & 1.0 & Triangular (min $0.87, \max 1.1$, mode 1.0$)$ & \\
\hline Penile cancer & 0.77 & Triangular (min 0.65, max 1.0, mode 0.67$)$ & \\
\hline Treatment for anogenital warts & $£ 112$ & Normal mean 112 (SD 4) & Desai et $\mathrm{al}^{19}$ \\
\hline \multicolumn{4}{|l|}{ Treatment for recurrent respiratory papillomatoses: } \\
\hline Juvenile cases & $£ 30000$ & Lognormal mean 30000 (SD 63000$)$ & \multirow[t]{2}{*}{ Hughes et $\mathrm{al}^{20}$ and unpublished data } \\
\hline Adult cases & $£ 4900$ & Lognormal mean 4900 (SD 5400) & \\
\hline Cytology test (liquid based) & $£ 54$ & Normal mean 54 (SD 13.5) & Curtis $^{24} ;$ Martin-Hirsch et $\mathrm{al}^{42} ;$ Karnon et $\mathrm{al}^{43}$ \\
\hline Colposcopy & $£ 144$ & Normal mean 144 (SD 36) & 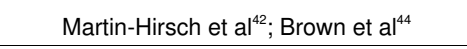 \\
\hline Pre-cancerous lesion treatment & $£ 349$ & Normal mean 349 (SD 87) & Martin-Hirsch et $\mathrm{al}^{42} ;$ Brown et $\mathrm{al}^{44}$ \\
\hline Vaccine price (per dose) & $£ 84.50$ & Fixed & British National Formulary ${ }^{41}$ \\
\hline Vaccine administration (per dose) & $£ 9.33$ & Fixed & $\begin{array}{c}\text { Department of Health, personal } \\
\text { communication }\end{array}$ \\
\hline \multicolumn{4}{|l|}{ Quality of life detriment } \\
\hline \multicolumn{4}{|l|}{ Treatment for } \\
\hline Cervical cancer & 0.285 & Triangular ( $\min 0.24, \max 0.33$, mode 0.285 ) & Myers et $\mathrm{al}^{46} ;$ Gold et $\mathrm{al}^{47}$ \\
\hline Vulvar-vaginal cancer & 0.32 & Triangular (min 0.16, max 0.52, mode 0.28) & Gold et $\mathrm{al}^{47}$ \\
\hline Anal cancer & 0.51 & Triangular $(\min 0.21, \max 0.83$, mode 0.49$)$ & Gold et $\mathrm{al}^{47}$ \\
\hline Oropharyngeal cancer & 0.25 & Normal mean 0.25 (SD 0.02) & Rogers et $\mathrm{al}^{52}$ \\
\hline Penile cancer & 0.29 & Triangular $(\min 0.2, \max 0.38$, mode 0.29$)$ & Institute of Medicine ${ }^{45}$ \\
\hline Recovery from cancer & 0.0305 & Triangular $(\min 0, \max 0.061$, mode 0.0305$)$ & Klee et $\mathrm{al}^{4950} ;$ Korfage et $\mathrm{al}^{51}$ \\
\hline Positive cytology result & 0.025 & Normal mean 0.025 (SD 0.00625) & Jit et $\mathrm{al}^{16}$ \\
\hline \multicolumn{4}{|l|}{ Positive cervical intraepithelial neoplasia result: } \\
\hline Grade I & 0.012 & Normal mean 0.012 (SD 0.003) & \multirow[t]{3}{*}{ Jit et $\mathrm{al}^{16}$} \\
\hline Grade II & 0.007 & Normal mean 0.007 (SD 0.00175) & \\
\hline Grade III & 0.054 & Normal mean 0.054 (SD 0.00135) & \\
\hline Episode of anogenital warts & 0.018 & Normal mean 0.018 (SD 0.0059) & Woodhall et $\mathrm{al}^{18}$ \\
\hline Episode of recurrent respiratory papillomatosis & 1.30 & Lognormal mean 1.30 (SD 1.56) & Bishai et $a^{58}$ \\
\hline Time spent receiving treatment for cancer (years) & 0.116 & Lognormal mean 0.116 (SD 0.36) & Hospital Episode Statistics \\
\hline \multicolumn{4}{|l|}{ True proportion of cancers due to HPV 16 and 18} \\
\hline Squamous cell carcinomas & $80 \%$ & Normal mean 0.80 (SD 0.027) & \multirow[t]{2}{*}{ Howell-Jones et $\mathrm{al}^{17}$} \\
\hline Adenocarcinomas & $86 \%$ & Normal mean 0.86 (SD 0.040) & \\
\hline Additional risk of mild smear if HPV 6 or 11 positive & $5.4 \%$ & Normal mean 0.54 (SD 0.030) & Chapman et $\mathrm{al}^{21}$ \\
\hline Risk of colposcopy after mild smear if HPV 6 or 11 positive & $2.3 \%$ & Normal mean 0.023 (SD 0.0072) & Chapman et $\mathrm{al}^{21}$ \\
\hline \multicolumn{4}{|l|}{ Proportion of cancers due to HPV: } \\
\hline Vulvar-vaginal cancer & $47 \%$ & Beta (p 690, q 780) & \multirow{4}{*}{$\begin{array}{l}\text { Literature review (see appendix } 1 \text { on } \\
\text { bmj.com) }\end{array}$} \\
\hline Anal cancer & $42 \%$ & Beta ( $p 55, q 77)$ & \\
\hline Oropharyngeal & $84 \%$ & Beta $(p 800, q 150)$ & \\
\hline Penile & $36 \%$ & Beta $(p 340, q 620)$ & \\
\hline \multicolumn{4}{|l|}{ Proportion of HPV attributed cancers due to HPV 16 or 18} \\
\hline Vulvar-vaginal cacer & $74 \%$ & Beta (p 77, q 27) & \multirow{3}{*}{$\begin{array}{l}\text { Literature review (see appendix } 1 \text { on } \\
\text { bmj.com) }\end{array}$} \\
\hline Anal cancer & $90 \%$ & Beta (p 95, q 11) & \\
\hline Oropharyngeal cancer & $93 \%$ & Beta (p 760, q 56) & \\
\hline
\end{tabular}


Table 2 (continued) 


\section{Figures}
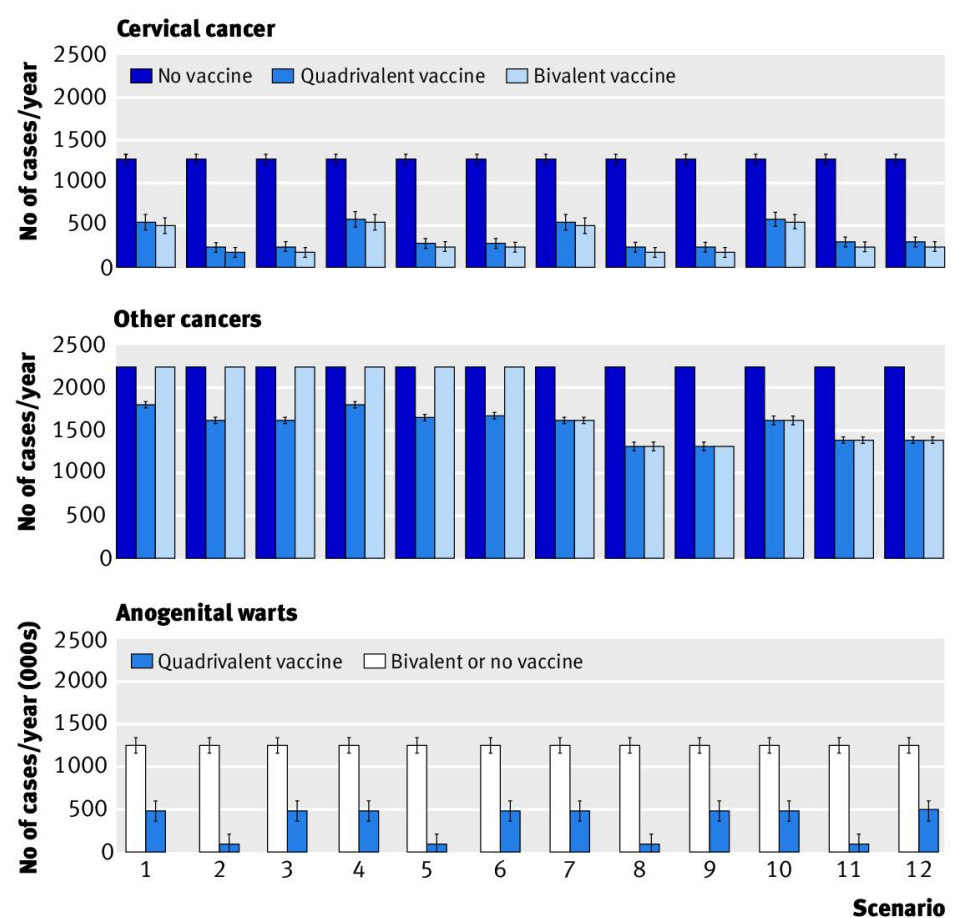

Fig 1 Estimated annual number of cases of cervical cancer, other HPV related cancers and vaccine HPV type warts in the year 2109 under the scenarios 1-12 described in table 1 (median of 10000 samples), given use of no vaccine, the quadrivalent vaccine, or the bivalent vaccine. Error bars show interquartile range of 10000 samples for each scenario (see appendix 2 on bmj.com for numerical results)
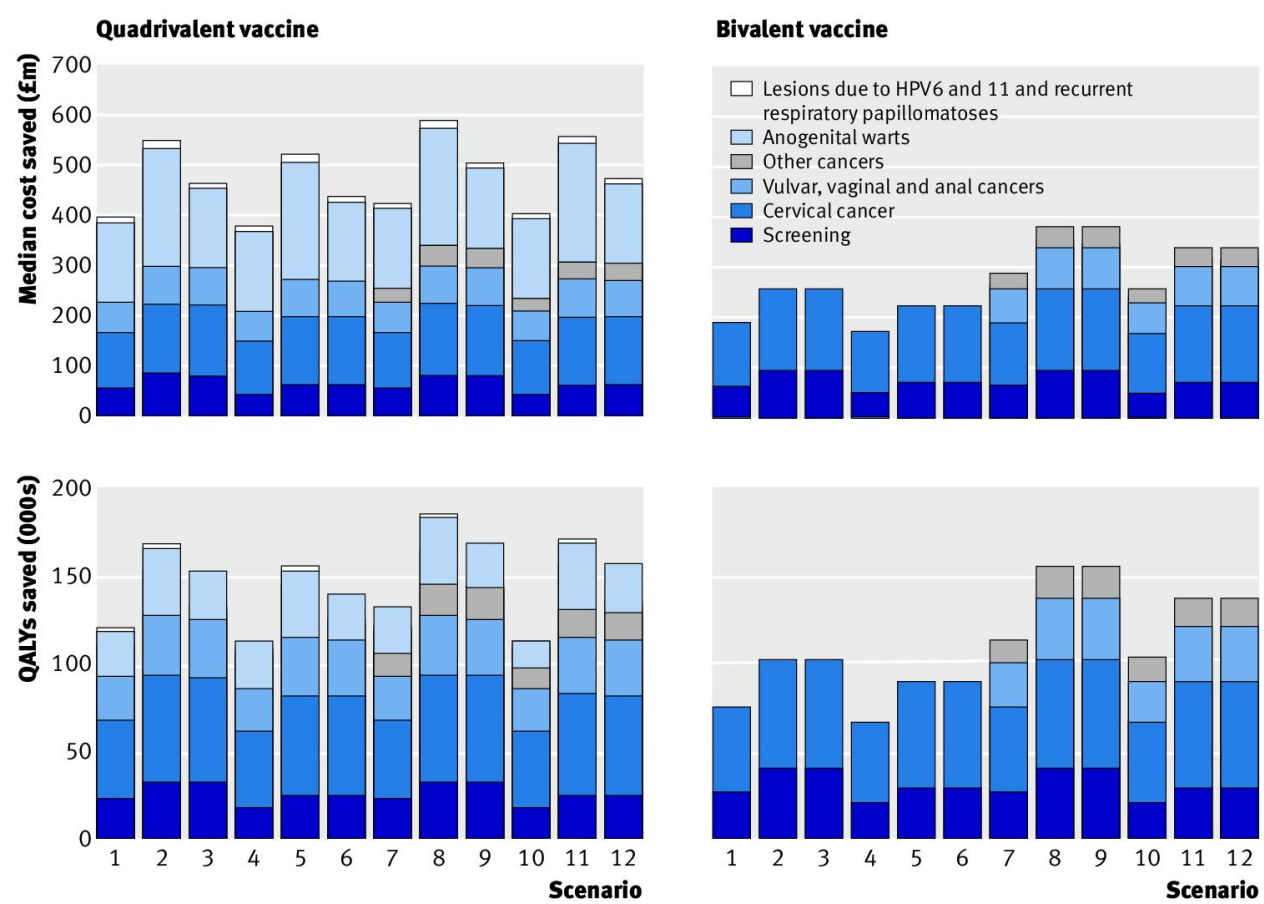

Fig 2 Discounted healthcare costs and QALYs saved over 97 years (2012-2109) of a quadrivalent or bivalent HPV vaccination programme (2012 onwards) under the different scenarios described in table 1 (median of 10000 samples) (see appendix 2 on bmj.com for numerical results and uncertainty intervals) 


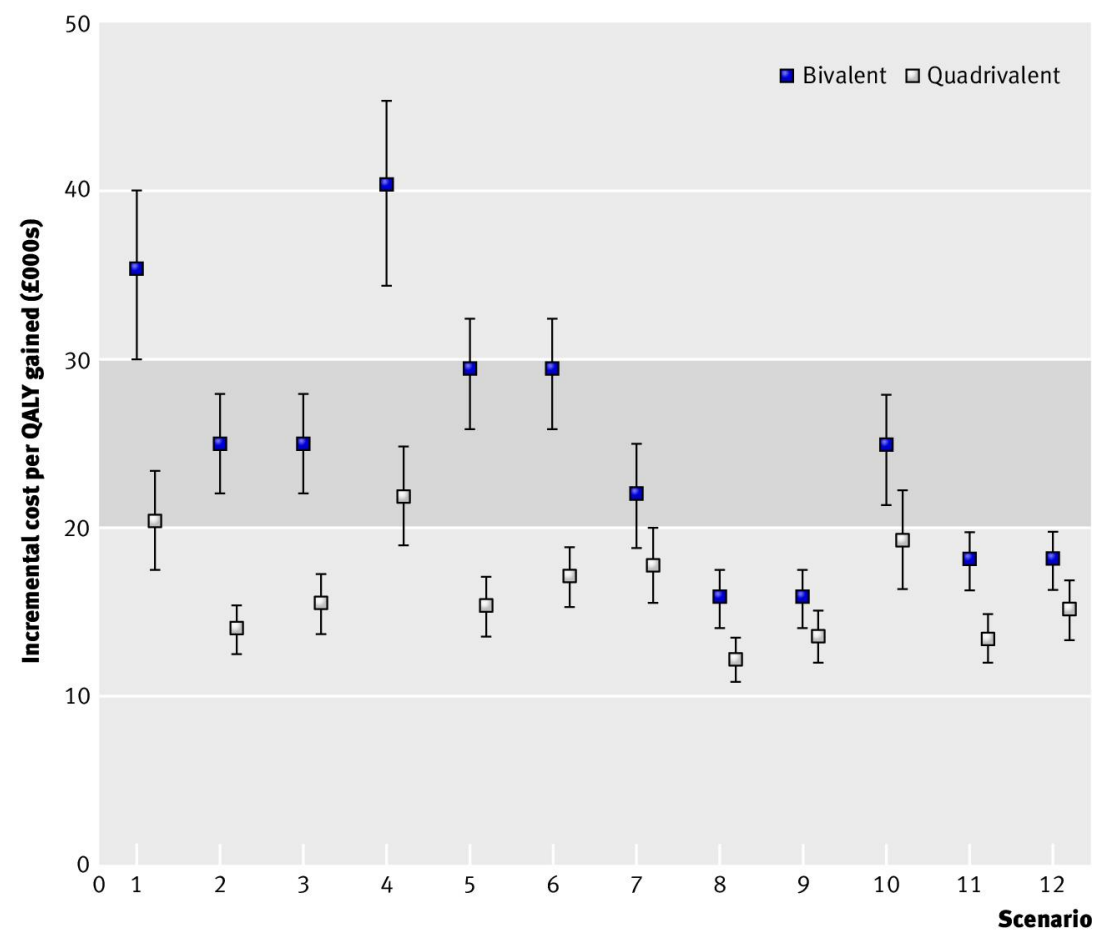

Fig 3 Incremental cost effectiveness ratios for equally priced quadrivalent and bivalent vaccines under the different scenarios described in table 1. Values show median (interquartile range) of 10000 Latin hypercube samples

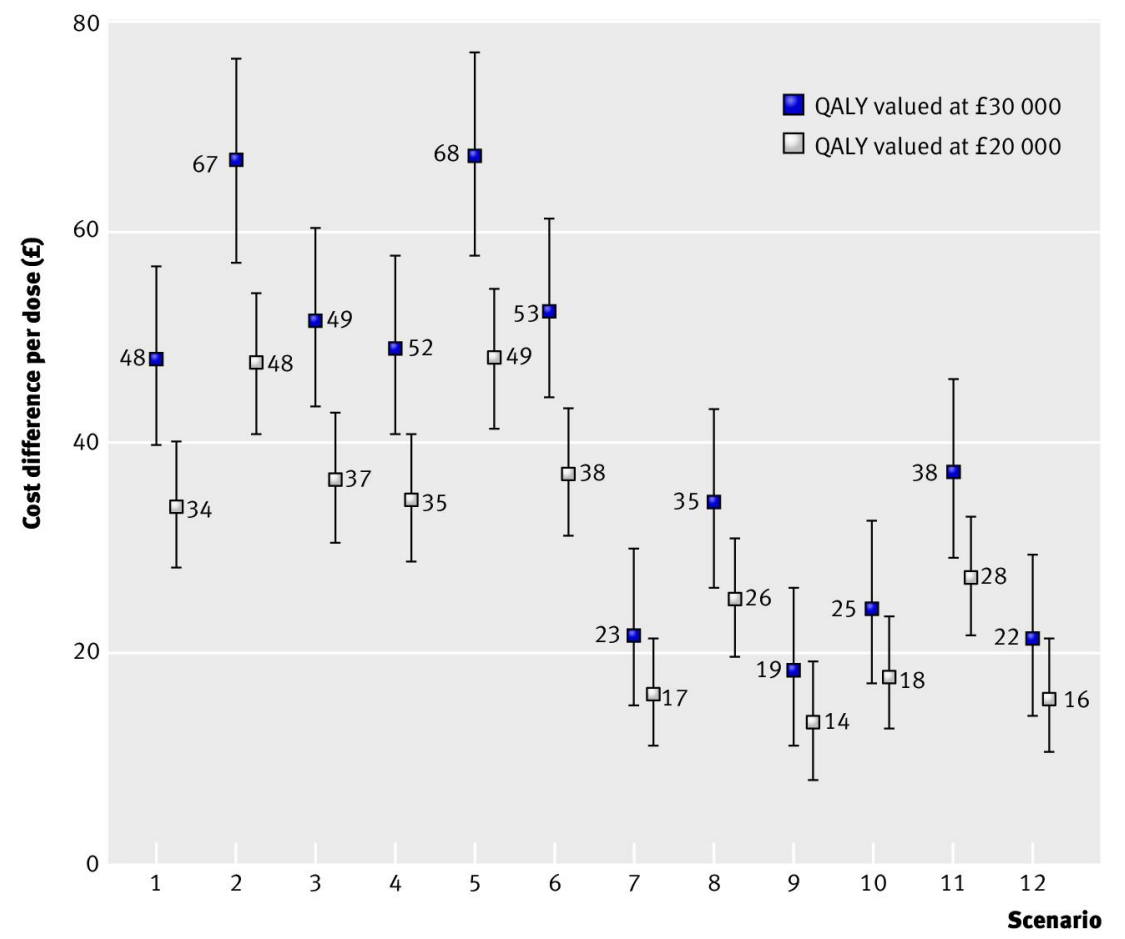

Fig 4 Additional cost per dose (for a three dose course) for the quadrivalent vaccine that makes it equally cost effective as the bivalent vaccine under the different scenarios described in table 1 and with one QALY valued at either £20 000 or £30 000. Values show median (interquartile range) of 10000 Latin hypercube samples 


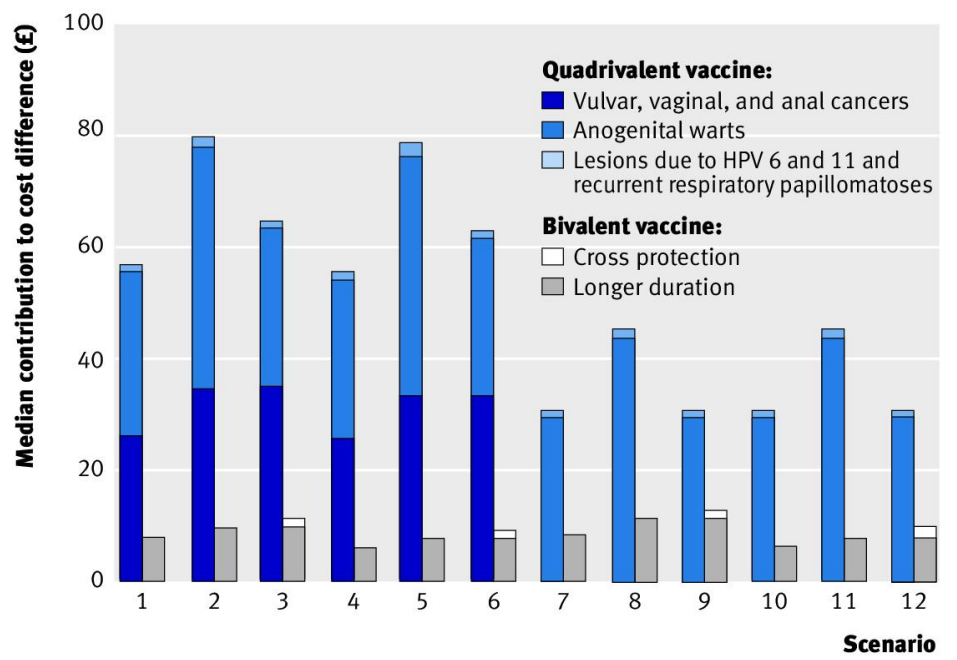

Fig 5 Benefits of the quadrivalent and bivalent vaccine that contribute towards the difference in price for the two vaccines to be equally cost effective (median of 10000 samples). One QALY is assumed to be valued at $£ 30000$. The two benefits of the bivalent vaccine (additional cross protection and in some scenarios longer duration) contribute negatively towards the price difference (that is, they make an equally cost effective quadrivalent vaccine cost less) (see appendix 2 on bmj.com for numerical results and uncertainty intervals) 